\title{
Correspondence
}

\section{Public awareness of psychiatry: media coverage}

\section{DEAR SIRS}

Recently there was an important European Conference of Child and Adolescent Psychiatry, with hundreds of delegates from all over the world. It was held in London and honoured by the presence of the Princess of Wales and the Minister for Health. In the same week, the Developmental Section of the British Psychological Society held its usual small annual conference in Cambridge. So how come only the BPS conference attracted any serious coverage in the national press? On Saturday 14 September alone the Guardian carried no less than three articles (on autism, on the effects of divorce on children, and on infantile envy) on work carried out by psychologists attending the Developmental Section, but nothing on the work presented by delegates to the European Congress.

My enquiries reveal that the BPS ensures that its conferences are supported by press committees composed of members of the relevant Section who are specially trained for the job. The articles in the Guardian were based on press releases written in advance by the press committee of the Developmental Section. So far as I am aware, the Child and Adolescent section of the College had no access to press committee support of this kind. The lack of media coverage can therefore perhaps be attributed to the lack of liaison rather than any lack of newsworthiness in the excellent presentations made. My contact in the BPS pointed out that the organisation has worked very hard over the last 15 years to create a public image of psychology as interesting, useful, scientifically respectable, and user-friendly. How different from the public image of psychiatry which continues to labour under a persistent burden of stigma and prejudice that diminishes our credibility and our effectiveness (the nefarious TV series 'Shrinks' provides a shining example!)

Is it not time to re-evaluate the appropriateness of our strategies for public relations and use of the media? Purchasers and managers, as well as our patients, could usefully be made more aware of the scope and value of what we have to offer. They may be interested to learn of the breadth and depth of our knowledge in both biological and cognitive science, and begin to appreciate and use our skills more creatively. Should we not try harder to help them understand the nature of the contributions we are able to make in such fields as child protection and mental illness prevention?
Sirs, how about a press committee for the Royal College Sections?

Waltham Forest Health Authority

GUINEVERE TUFNELL

Child \& Family Consultation Service

\section{Shernhall Street}

London E17 $3 E A$

\section{DeAR Sirs}

We would like to thank Dr Tufnell for pointing out the excellent relationship that has been established between the British Psychological Society and the Guardian. Any more information on how this link has been forged and subsequently maintained would be extremely useful to our Public Education Committee.

However, the rest of Dr Tufnell's letter I simply cannot accept. The Princess of Wales' famous "hugs" speech was reported on national television and became a saying of the week, and will undoubtedly be remembered and quoted long-term. I am afraid that Government Ministers saying nice things about professional organisations never gets much media cover!

The publicity from the Annual Meeting of the College was similarly widespread, both on television and in most of the national and many local newspapers. In particular, the Prince of Wales' speech was very widely quoted with a wide range of comments. However, the scientific programme was not neglected and there were usually two or three research papers commented upon in the media each day for the five days of the meeting.

There is undoubtedly stigma associated with the mentally ill and with psychiatry, and the Prince of Wales' speech in part addressed this. I do not think that most psychologists would consider their image any better than that of psychiatry and we really need to work together in improving the image and lessening stigma. The Public Education Committee of the College has made considerable progress in the last few years in putting over a more accessible side to psychiatry and among many possible examples, one would be that the College has now supplied over one million leaflets in the series, 'Help is at Hand'.

Certainly we need to be vigilant in improving our public education but Dr Tufnell's letter seems to show a lack of awareness for what is already being done-and this in itself is part of the public image which we need to improve!

Professor A. C. P. Sims President 